\title{
TWO PORTS VERSUS FOUR PORTS LAPAROSCOPIC CHOLECYSTECTOMY (THE USE OF STRATEGIC EXTRACORPOREAL STITCHES)
} By

SAMEH ELSEBAIE ${ }^{1}$, HESHAM ABDELAZIZ ${ }^{1}$, AMR MUSTAFA ${ }^{1}$, AHMED ABDELAZIZ ${ }^{1}$, YASSER A. ELSAYED ${ }^{2}$ and MOHAMED ABDELHALIM ${ }^{1}$ Department of General Surgery, Theodor Bilharz Research Institute Hospitals ${ }^{1}$, Imbaba P. O. B. 30, Giza and Military Medical Academy², Cairo 11291, Egypt

( ${ }^{*}$ Correspondence:Hesham1983@hotmail.com)

\section{Abstract}

Four ports laparoscopic cholecystectomy (LC) has been the standard for treatment of the symptomatic cholelithiasis. Herein, the experience of two-ports LC regarding its safety and feasibility was given. This study was conducted in Theodor Bilharz Research Institute (TBRI) in the period from November 2017 till April 2018, as a prospective randomized study including one hundred patients with chronic calcular cholecystitis, which were divided into two equal groups. The study compared between group A (GA) which underwent four ports LC and group $\mathrm{B}(\mathrm{GB})$ which underwent two ports LC.

The results showed that in GA, no cases were converted to open cholecystectomy. But, in GB only two patients converted to three-port laparoscopic cholecystectomy. There were no intraoperative complications encountered in any patient in both groups. In GA, operative time ranged between 28-62 minutes (mean \pm 44.57 ) while in GB, operative time ranged between 39-134 minutes (mean \pm 59.93 ); with hospital stay of three days in both groups. The pain score showed statistically significant differences regarding port-site pain $(\mathrm{P}$ value $=0.040)$. Significant lower analgesic demands were recorded in the 2 ports group. Scar satisfaction showed a marked statistically significant differences regarding the aesthetic results between the two groups ( $\mathrm{P}$ value $=0.0319$ )

Key Words: Patients, Laparoscopic Cholecystectomy, Two ports, Extra-corporeal stitches.

\section{Introduction}

Laparoscopic cholecystectomy (LC) is the 'gold standard' for cholelithiasis treatment. Short length of hospital stay, immediate regaining of physical activity, low prevalence of postoperative pain, morbidity and mortality, and good cosmetic outcomes contribute to the benefits of the laparoscopic cholecystectomy (Sari et al, 2005). LC has undergone many refinements including reduction in the port size. The two ports laparoscopic cholecystectomy has been reported in the international literature to be safe and feasible (Dubois et al, 1990).

The introduction of the single port laparoscopic cholecystectomy (LC) has drawn as much attention and the interest as the initial introduction of the LC (Hayashi et al, 2010). It provides nearly scar-less wound. However, it was not proved to have the other potential benefits such as reducing the postoperative pain and return to the normal activity (Strasberg, 2012). In the four port LC, the critical view of safety was the best ensured by the three instruments, which enable both attainment of sufficient operative vision and bimanual manipulation. But, as number of incisions for the ports increased, the potential risks of the port related complications increased as well. Thus, the patients have growing aware ness of the life quality that increased their cosmoses demand (Streenivas et al, 2014).

This study aimed to evaluate the two ports versus the four ports of the laparoscopic cholecystectomy (Demographic data such as age, sex, \& BMI, conversion of cases to open cholecystectomy or more than two ports LC, operative time, intraoperative complications) as the bleeding, bile leakage, GB perforation, post-operative complications (wound infection) the pain, analgesia scores and scar satisfaction. 


\section{Materials and Methods}

This study included a total of 100 patients with chronic calcular cholecystitis as evaluated by history, clinical examination and investigations. However, patients with acute cholecystitis proved clinically or radiologically or patients suspected to have malignancy proved by the ultrasound or the computed tomography (CT), pregnancy, or the patients have excess intraoperative adhesions that necessitate at least 2 ports for manipulation will be excluded from the study. The one hundred patients with symptomatic chronic calcular cholecystitis were randomly divided into 2 equal groups. Patients of GA underwent four ports laparoscopic cholecystectomy and those of GB underwent two ports laparoscopic cholecystectomy. Besides, the written informed consent was taken from each patient before enrolling in the study.

Endoscopic dissectors, scissors, graspers, Maryland and hooks, monopolar electrocautery clip applier $5 \mathrm{~mm}, 30 \mathrm{o}$, or zero $10 \mathrm{~mm}$ camera, suction instrument and 2 straight needles (Proline 2/0) with cutting end.

Operative technique: Patients were placed in the supine position with the operating surgeon standing on the patient's left. As regards group A (Four Ports technique), trocars were on semi-circle shape (American position); one $10 \mathrm{~mm}$ optical port above or below the umbilicus, one $10 \mathrm{~mm}$ operating port in the epigastrium, one $5 \mathrm{~mm}$ operating port in the right hypochondrium and one $5 \mathrm{~mm}$ assistant port in anterior axillary line. Pneumoperitoneum was established by Hasson method (open method). Dissection of Callot's triangle identified cystic artery and cystic duct. This was done by Maryland or monopolar electrocautery. The clipping of the cystic artery, and cystic duct were by dissection of gallbladder from the liver bed. Extraction of gall-bladder through epigastric port, occasionally drain was inserted through anterior axillary line port, if needed. As to the GB (Two port technique), Pneumoperitoneum was established by Hasson's method (open method). Umbilical port $10 \mathrm{~mm}$ was inserted and telescope was inserted into it. Epigastric port $10 \mathrm{~mm}$ was inserted. One traction suture was placed in the fundus of gallbladder using Proline $2 / 0$ on straight needle with cutting or round end and passed through anterior abdominal wall; and then placed high up in the right hypochondrium, in the last intercostal space; extracorporeal knot was done. Another traction suture was passed through anterior abdominal wall and placed in the infundibulum of gallbladder. Then intracorporeal knot was done over the Hartman's pouch and the needle (Proline 2/0 on the straight needle on cutting end) was passed via lateral abdominal wall in right flank, Occasionally, a third traction suture was applied through body of the gallbladder if traction of the gallbladder was not enough. Manipulation of the gallbladder with sutures was done to reveal Callot's triangle. Cystic artery and duct were dissected and clipped. The gallbladder was separated from the liver bed, and extracted by epigastric port. Drain inserted through epigastric port if needed.

\section{Results}

The age of the patients ranged between 2257 years old with mean \pm SD $40.04 \pm 6.48$ for GA and $35.90 \pm 8.12$ for GB. GA included 42 females \& 8 males. GB included 44 females \& 6 males. The patients with BMI ranged from 24 to 37. Measurement of the BMI in all patients was done to test the feasibility of the 2-ports technique in the obese patients. During operation, in GB, only one prolene stitch applied to liver in single patients because of prolapsed liver. In GA, no cases were converted to open cholecystectomy. In GB only 2 patients converted to three-port laparoscopic cholecystectomy, due to fatty omentum that obscure the field, so put an additional port to push it down to facilitate the procedure. There were no intra-operative complications encountered in any patient in both groups, except the GB perforation that occurred in two patients of GA, and in three patients of GB. In GA, the operative time ranged between 28-62 minutes with mean 44.57 while in GB, operative time ranged 
between 39-134 minutes with mean 59.93. Operative time is a time between the skin incisions till the end of the operation. In GA, there were 23 patients with no drain and 27 patients with the drain postoperative; with hospital stay of 3 days. In GB, there were 18 patients with no drain postoperative and 32 patients with drain; with hospital stay of 3 days in both groups (to test pain during this period. The TLC compared between the two groups postoperatively to detect if there is any infection occurred after any procedure. For monitoring and comparing the port-site pain intensity 3 days postoperatively between both groups, a visual analog scale (VAS) with a $10 \mathrm{~cm}$ vertical score ranging from "no pain" (score 0) to "worst possible pain" (score 10) was used. After the patients had been adequately instructed about the range for measuring pain, they selected a value on the scale (between $0 \& 10$ ). Pain score analyses showed significant differences postoperatively regarding port-site pain $(\mathrm{p}=$ 0.040 ). The patients in the four port group were usually reported the significantly higher pain scores. The significant lower I.V. analgesic demands were recorded in the two ports group versus the four ports group, both, early post-operatively $(\mathrm{p}=0.031)$ and that went in line with the postoperative portsite pain intensity that both groups had experienced.

For reporting and comparing the patients' satisfaction with the aesthetic results of both procedures during the follow ups between the two groups, a visual analog scale with a $10 \mathrm{~cm}$ vertical score ranging from the "very dissatisfied" (score 0) to "very satisfied" (score 10) was used. After the patients had been adequately instructed about the range for measuring their satisfaction with the scar, they selected the value on the scale (between 0 and 10).

The scar satisfaction analyses showed the marked statistically significant differences regarding the aesthetic results between both groups $(\mathrm{p}$ value $=0.0319)$.

The details were given in tables $(1,2,3,4$, $5 \& 6)$ and figures ( $1 \& 2)$.

Table 1: Distribution of BMI in both groups.

\begin{tabular}{|c|c|c|c|c|c|c|c|c|}
\hline Groups & \multicolumn{5}{|c|}{ BMI } & \multicolumn{3}{c|}{ T-test } \\
\hline & \multicolumn{3}{|c|}{ Range } & Mean & \pm & SD & t & P-value \\
\hline GA & 24.0 & - & 36.0 & 29.53 & \pm & 3.68 & \multirow{2}{*}{0.669} & \multirow{2}{*}{0.506} \\
\hline GB & 24.0 & - & 37.0 & 28.93 & \pm & 3.25 & & \\
\hline
\end{tabular}

Table 2: Rate of conversion of cases in both groups.

\begin{tabular}{|l|c|c|c|c|c|c|}
\hline \multirow{2}{*}{ Conversion } & \multicolumn{2}{|c|}{ GA } & \multicolumn{2}{c|}{ GB } & \multicolumn{2}{c|}{ Total } \\
\cline { 2 - 7 } & No. & $\%$ & No. & $\%$ & No. & $\%$ \\
\hline No & 30 & 100.0 & 27 & 90.0 & 57 & 95 \\
\hline Converted to open & 0 & 0.0 & 1 & 3.3 & 1 & 1.7 \\
\hline Converted to 3 ports & 0 & 0.0 & 2 & 6.7 & 2 & 3.3 \\
\hline Total & 30 & 100.0 & 30 & 100.0 & 60 & 100.0 \\
\hline Chi-square $X^{2}$ & \multicolumn{7}{|c|}{0.158} \\
\hline Chi-square P. value & \multicolumn{7}{|c|}{0.206} \\
\hline
\end{tabular}

Table 3:-Intraoperative complication

\begin{tabular}{|c|c|c|c|c|c|c|}
\hline \multirow{2}{*}{$\begin{array}{l}\text { Intraoperative } \\
\text { complications }\end{array}$} & \multicolumn{2}{|c|}{ GA } & \multicolumn{2}{c|}{ GB } & \multicolumn{2}{c|}{ Chi-square } \\
\cline { 2 - 7 } & No. & $\%$ & No. & $\%$ & $\mathrm{X}^{2}$ & P-value \\
\hline Bleeding & 0 & 0.0 & 0 & 0.0 & 0.00 & 1.000 \\
\hline Biliary injury & 0 & 0.0 & 0 & 0.0 & 0.00 & 1.000 \\
\hline GB perforation & 2 & 6.7 & 3 & 10.0 & 0.07 & 0.987 \\
\hline
\end{tabular}

Table 4: Operative time of cases in both groups

\begin{tabular}{|c|c|c|c|c|}
\hline Groups & \multicolumn{2}{|c|}{ Operative time } & \multicolumn{2}{c|}{ T-test } \\
\hline & Range & Mean \pm SD & T & P-value \\
\hline GA & $28.0-62.0$ & $44.57 \pm 7.73$ & \multirow{2}{*}{5.402} & $<0.001$ \\
\hline GB & $39.0-134$ & $59.93 \pm 19.8$ & & \\
\hline
\end{tabular}


Table 5: Comparison between groups as to mean pain score $\&$ analgesia score

\begin{tabular}{|l|c|c|c|c|}
\hline \multicolumn{5}{|c|}{ Pain score } \\
\hline Day & GA & GB & T-test & P value \\
\hline First day (mean) & 8 & 5.4 & \multirow{2}{*}{0.8238} & 0.0404 \\
\hline Second day (mean) & 6.65 & 4.1 & & \\
\hline Third day (mean) & 5.85 & 2.4 & & \\
\cline { 1 - 2 } \multicolumn{5}{|c|}{ Analgesia score } \\
\cline { 1 - 3 } First day (mean) & 2.5 & 1.8 & & \\
\hline Second day (mean) & 1.9 & 1.1 & 0.7929 & \\
\hline Third day (mean) & 1.1 & 0.7 & & \\
\hline
\end{tabular}

Table 6: Scar satisfaction: Score (1-10).

\begin{tabular}{|c|c|c|}
\hline Scar satisfactions & GA & GB \\
\hline No. & 30 & 30 \\
\hline Mean & 7.7333 & 4.26 \\
\hline SD & 0.865 & 1.143 \\
\hline P value & \multicolumn{2}{|c|}{0.0319} \\
\hline
\end{tabular}

\section{Discussion}

The gallstones grow inside gallbladder or biliary tract (cholelithiasis). These can be asymptomatic or symptomatic; only gallstones with symptoms or complications are defined as gallstone disease (Boškoski et al, 2019). Based on their composition, gallstones are classified into the cholesterol gallstones, which represent predominant entity, and bilirubin (pigment) stones. Black pigment stones can be caused by chronic haemolysis; brown pigment stones typically developed in obstructed and infected bile ducts.

There are some modifications in the technique of laparoscopic cholecystectomy. The use of fourth trocar, which is generally used for the gallbladder funds retraction, in the American Technique was deemed unnecessary. Some surgeons used sutures to retract the gallbladder (Dubois et al, 1990).

The introduction of single port laparoscopic cholecystectomy has drawn as much attention and interest as initial introduction of the LC (Rivas et al, 2010). In the metaanalysis of 45 studies (Joseph et al, 2012), on 2626 patients) on single port LC, the rate of bile duct injury was significantly higher in single port than in the 4 ports LC $(0.72 \%$ versus $0.50 \%$, respectively). It could be attributed to the difficulties in securing "critical view of safety", the clear view of the structure included cystic duct, common bile duct and the liver during dissection in the single port LC (Strasberg et al, 1995).
The parallel instrumental alignment and loss of triangular retraction hinder the critical view of safety in the single port LC (Strasberg, 2012). The four ports LC proved to be standard for treatment of symptomatic cholelithiasis, as verification of its safety and feasibility (NIH, 1993). Although the three ports LC were introduced thereafter, yet it could not replace the four port LC completely due to limited evidence (Sun $e t$ al, 2009). In four ports by 3 instruments, which enable both attainment of sufficient operative vision and bimanual manipulation. However, as the number of incision for ports increase the potential risks of port related complications also can increase. Besides, as patients have growing awareness of the quality of life, there has been an increase in demand for the cosmoses. Few literature evaluated the feasibility of this technique (the two ports) because its difficulty. So, this study aimed to test the feasibility of this technique. A report on the two ports laparoscopic cholecystectomy has already shown that all patients would choose this technique over the four-port approach, as the postoperative pain was significantly reduced and the procedure was cosmetically more acceptable to the patients (Trichak, 2011).

The two ports laparoscopic cholecystectomy proved to be the safe and feasible, but it was technically difficult even in expert hands because of limited operative field. The modification of the operating telescope 
to achieve a wider field of view was done (Langwieler et al, 2009). Using modified operating telescope gave the initial value of two ports laparoscopic cholecystectomy.

In the present study, operation was done by thirty-degree telescopes to make better visualization of field. Tagaya et al. (1999) reported a new technique of laparoscopic cholecystectomy by the two ports approach using abdominal wall lifting method. They noticed that retraction of the gall bladder is possible by the insertion of forceps through the umbilical port along the telescope which might eliminate the necessity of creating the third port. Kagaya (2001) developed a twinport system that allowed a 5-mm camera and a forceps to be inserted through a single port. A 5-mm trocar is inserted approximately one $\mathrm{cm}$ below the xiphoid process, and the laparoscopic cholecystectomy was done via two ports. Lee et al. (2005) developed the two ports needlescopic cholecystectomy by using the $2 \mathrm{~mm}$ or $3 \mathrm{~mm}$ endograspers. Mishra has developed a unique technique with extra corporeal knot to perform two ports laparoscopic cholecystectomy.

The present study used two traction sutures passed via the fundus and neck of the gall bladder respectively, with good results. As regards the fundus stich, it took about 2 minutes but if GB contracted was slightly difficult in picking up GB, stich took about 4 minutes. Hartman pouch stitch, often 1 stitch, if redundant GB or long GB slightly lateral to midclavicular line 2 to 4 fingers below last ribs, but sometimes, mild difficulties in dissecting the posterior wall of GB on the right side.

Alternative techniques can be applied, both by making a knot at Hartman pouch, and going out by needle near midline. Other options were to put a new stitch in the previous site near midline to manipulate GB. By using one of the above mentioned techniques, the straight forward cholecystectomy was easy. In the patients with large liver lobe or redundant and obscure field, extra-corporeal stitch was used to liver retract.
The current study found that pain was less in the two ports laparoscopic cholecystectomy patients than four ports laparoscopic cholecystectomy. The patient scar satisfaction in two ports laparoscopic cholecystectomy was better ( 2 wounds only instead of 4 wounds). This agreed with Elwan et al. (2013). The disadvantages were the slightly long operative time, bile spillage, and in rare cases, gallbladder rupture during the procedure. In cases with ruptured gallbladder, stones could be extracted using stone forceps or glove. There were no postoperative complications in both groups. The two ports cholecystectomy was done in patients with BMI $>30$ without any complication.

\section{Conclusion}

The two ports laparoscopic cholecystectomy proved to be a feasible and safe technique in straight forward cases using extracorporeal stitches instead of graspers in traction and manipulation of gallbladder or liver. More large scale clinical trials are ongoing to modify and improve this approach.

\section{References}

Boškoski, I, Konikoff, FM, Ben Muvhar, S, Tringali, A, Tsehori, J, et al, 2019: A novel gallbladder umbrella stent (the Shai ${ }^{\text {TM }}$ Stent) for prevention of stone migration and impaction: results on feasibility and short-term safety in a porcine model. Surg. Endosc. 33, 9:3050-35.

Dubois, F, Icard, P, Berthelot, G, Levard, H, 1990: Coelioscopic cholecystectomy: Preliminary report of 36 cases. Ann. Surg. 211:60-2.

Elwan, AM, Abomera, MA, Atwa, NS, Makarem, AA, 2013: Comparative study between the two port and four-port laparoscopic cholecystectomy. J. Arab Soc. Medical Res. 33:3-8.

Hayashi, M, Asakuma, M, Komeda, K, Miyamoto, Y, Hirokawa, F, et al, 2010: Effectiveness of a surgical glove port for single port surgery. World J. Surg. 34:2487-9.

Joseph, M, Phillips, MR, Farrell, TM, Rupp, CC, 2012: Single incision laparoscopic cholecystectomy is associated with a higher bile duct injury rate: A review and a word of caution. Ann. Surg. 256:1-6.

Kagaya, T, 2001: Laparoscopic cholecystectomy via two ports using the twin-port system. J. Hepatobil. Pancreat. Surg. 8:76-80. 
Lammert, F, Gurusamy, K, Ko, CW, Miquel, JF, Méndez-Sánchez, N, et al, 2016: Gallstones. Nat. Rev. Dis. Primers. 2:16024-30.

Langwieler, TE, Nimmesqern, T, Back, M. 2009: Single port access in laparoscopic cholecystectomy. Surg. Endos. 23:1138-41.

Lee, KW, Poon, CM, Leung, KF, Lee, DWH, 2005: Two port needlescopic cholecystectomy: Prospective study in 100 cases. Hong Kong Med. J. 11:30-5.

NIH, 1993: Gallstones and laparoscopic cholecystectomy. JAMA 269:1018-24.

Poon, CM, Chan, KW, Ko, CW, Chan, KC, Lee, DW, et al, 2002: Two port laparoscopic cholecystectomy: Initial results of a modified technique. J. Laparoendosc. Adv. Surg. Tech. 12, 4:259-62.

Rivas, H, Varela, E, Scott, D, 2010: Single incision laparoscopic cholecystectomy: Initial evaluation of a large series of patients. Surg. Endose. 24:1403-12.

Sari, YS, Tunali, V, Tomaoglu, K, Karago“z, B, Güneyi, A, et al, 2005: Can bile duct injuries be prevented? A new technique in laparoscopic cholecystectomy. BMC Surg. 5:14-8.
Strasberg, SM, 2012: Single incision laparoscopic cholecystectomy and introduction of innovative surgical procedures, Ann. Surg. 256:e7-9.

Strasberg, SM, Hertl, M, Soper, NJ, 1995: An analysis of the problem of biliary injury during laparoscopic cholecystectomy. J. Am. Coll. Surg. 180:101-15.

Streenivas, S, Mohil, RS, Singh, GJ, Arora, J K, Kandwal, V, 2014: Two-port mini laparoscopic cholecystectomy compared to standard four port laparoscopic cholecystectomy. J. Minim. Access Surg. 10:190-6.

Sun, S, Yang, K, Gao, M, He, X, Tian, J, 2009: Three-port versus four-port laparoscopic cholecystectomy: meta-analysis of randomized clinical trials. World J. Surg. 33:1904-8.

Tagaya, N, Fukutomi, K, Kogure, H, 1999: New two port technique for laparoscopic cholecystectomy: A preliminary report. Dokkyo J. Med. Sci. 26:419-22 .

Trichak, S, 2003: Three-port versus standard four-port laparoscopic cholecystectomy. Surg. Endosc. 17:1434-6.

Wani, I, 2011: Gallbladder ascariasis. Turk. J. Gastroenterol. 22, 2:178-82

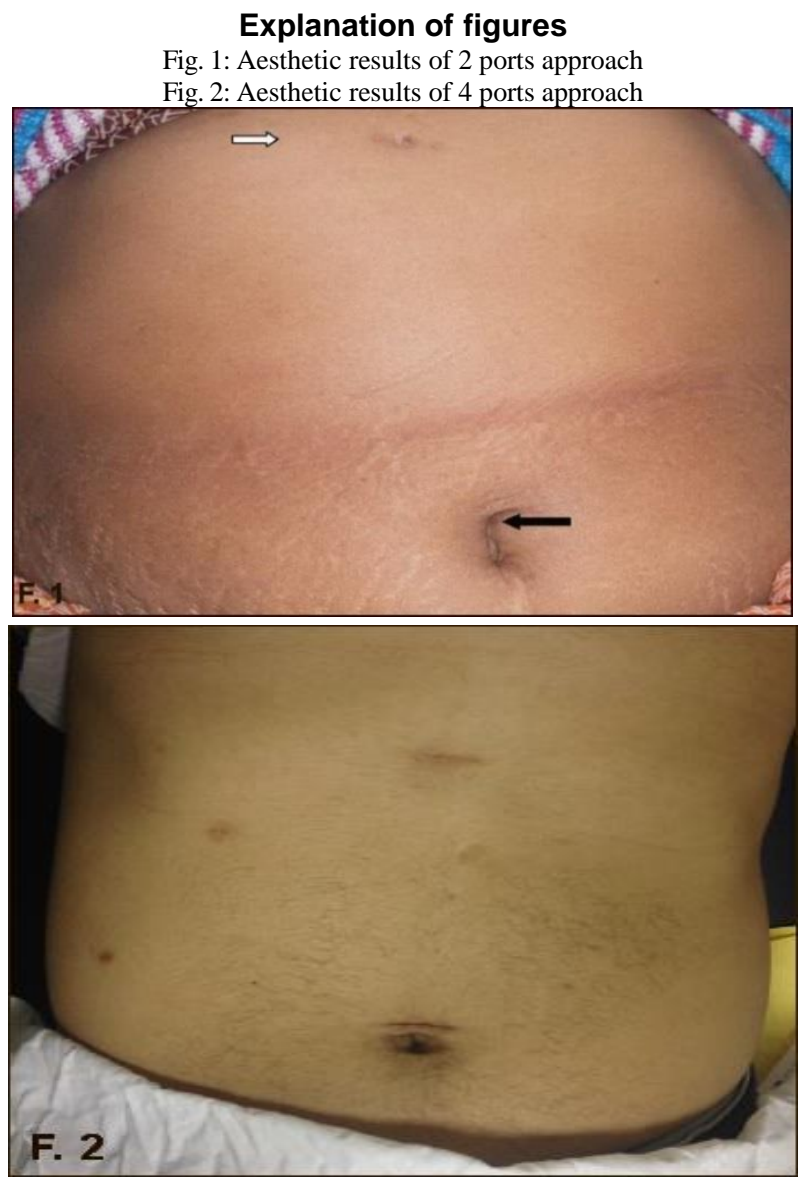

